\title{
APPLICATIONS TO A THEORY OF BONUS SYSTEMS
}

\author{
S. VEPSÄLÄINEN \\ Helsinki
}

This paper deals with bonus systems used in Denmark, Finland, Norway, Sweden, Switzerland and West Germany. These systems are studied by methods given by Mr. Loimaranta ${ }^{1}$ ). The bonus rules of Denmark and Sweden have been modified because they contradict to one of the assumptions of the theory.

It is assumed that the number of claims in a year follows the Poisson distribution with a mean $\lambda$. Further it is assumed that the value of $\lambda$ is independent of time.

In each case bonus rules are given in form of transformations $T_{k}$ defined in ref. I., i.e. $T_{k}(i)=j$ when a policy moves from class $i$ to class $j$ after $k$ claims. The class where a new policy starts from is called the initial class. Bonus scales, the vectors $B$, are normed so that the premium of the initial class is roo.

For each bonus system the efficiency $\eta$ of the system and the discrimination power $d$ of the bonus rules as a function of the mean claim frequency $\lambda$ have been calculated. The graphs of these functions are presented in the figures 2 to 4 respectively. In the following pages, different bonus rules are described in detail and some simple analysis based on the curves on pp. 2II-2I4 has been made. The calculations were performed quite recently and any deeper analysis of the results has not been possible because of lack of time.

\section{Denmark}

In order to be able to apply the theory of Markov chains to a bonus system we must require among others that the transition to a certain class depends only on the number of claims occurred during last period ignoring possible former claims. The Danish system has originally four bonus classes labeled from o to 3 .

1) K. Loimaranta: Some Asymptotic Properties of Bonus Systems Astin Colloquium I970, Randers. 


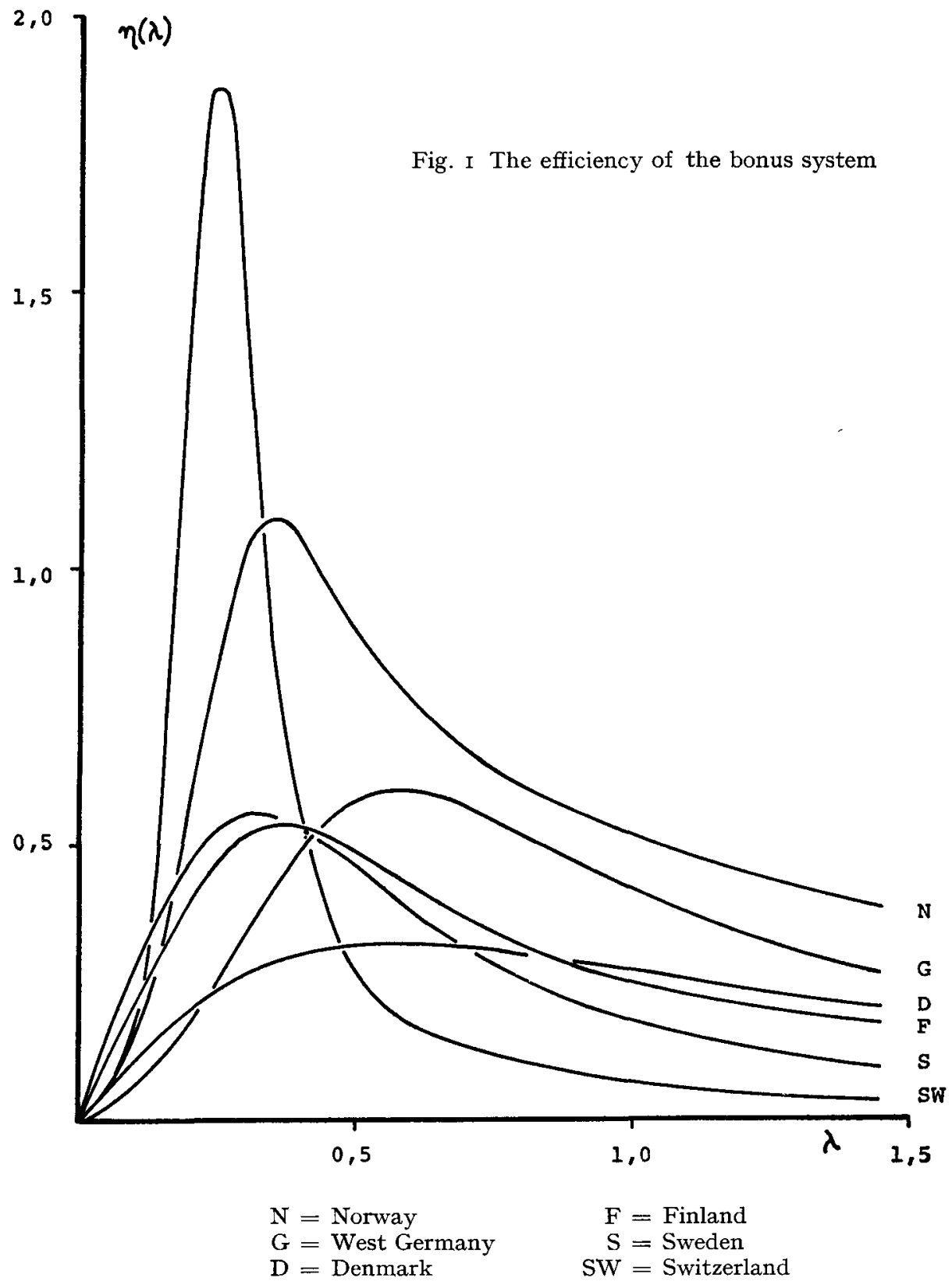




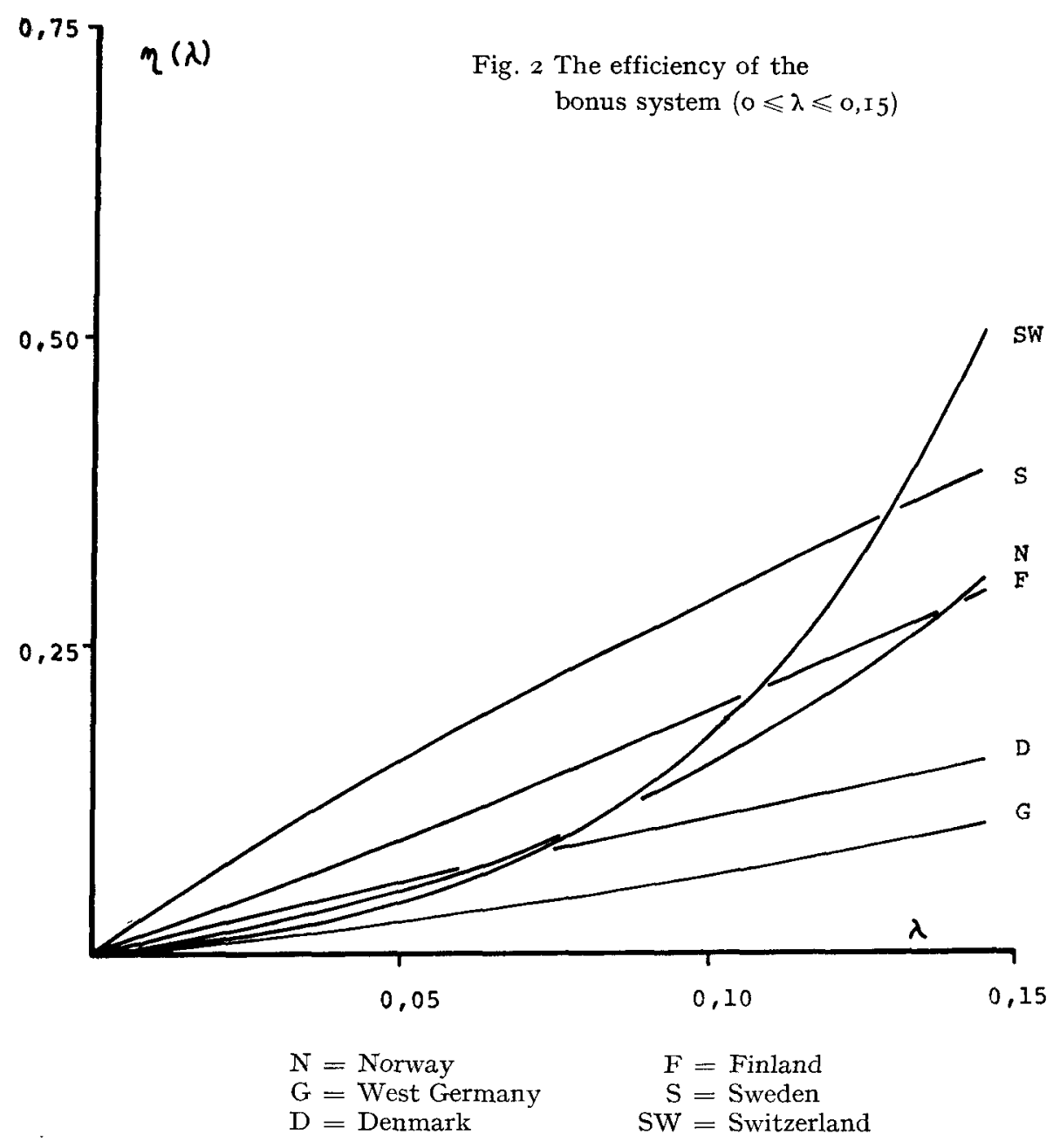




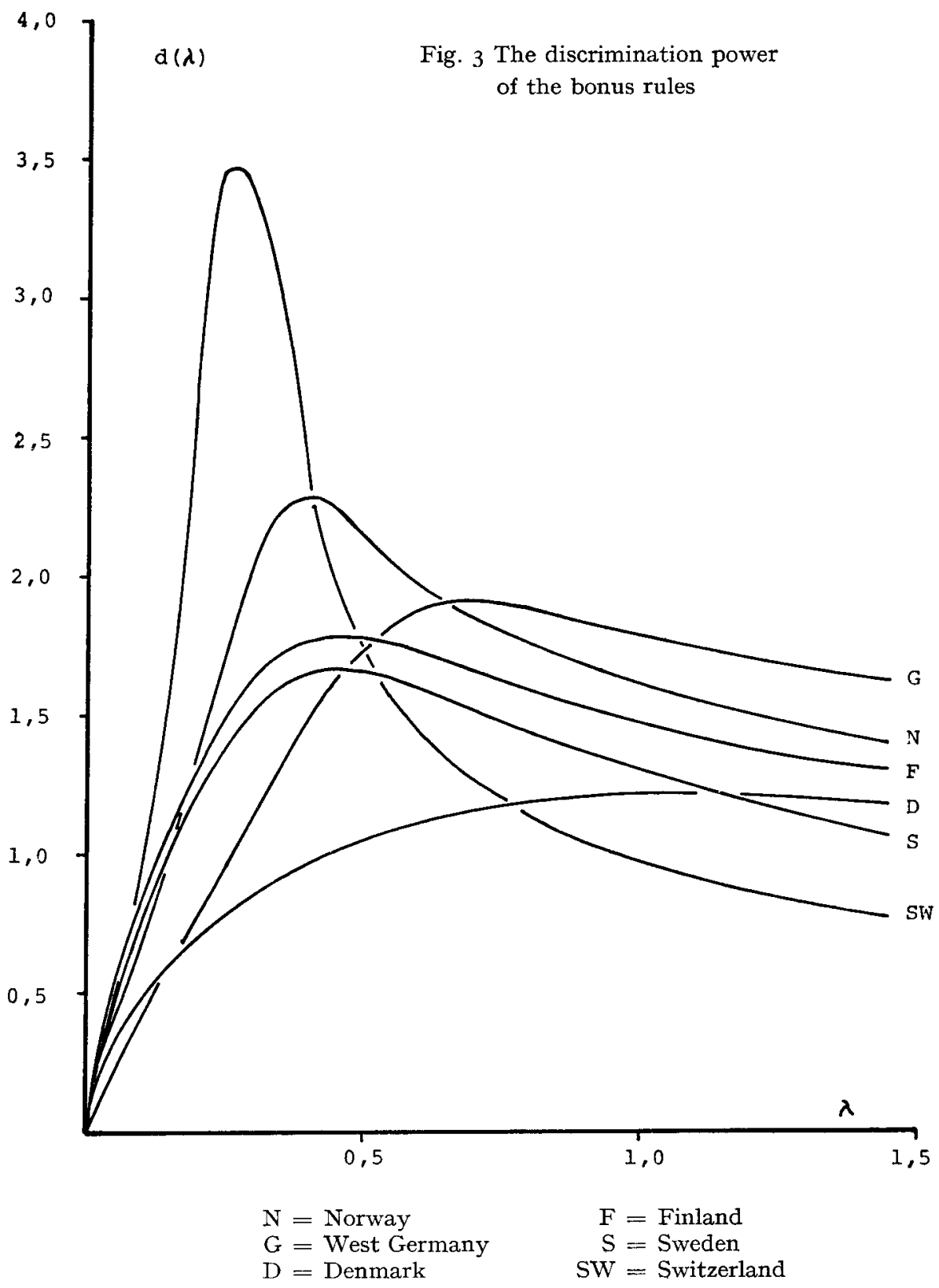




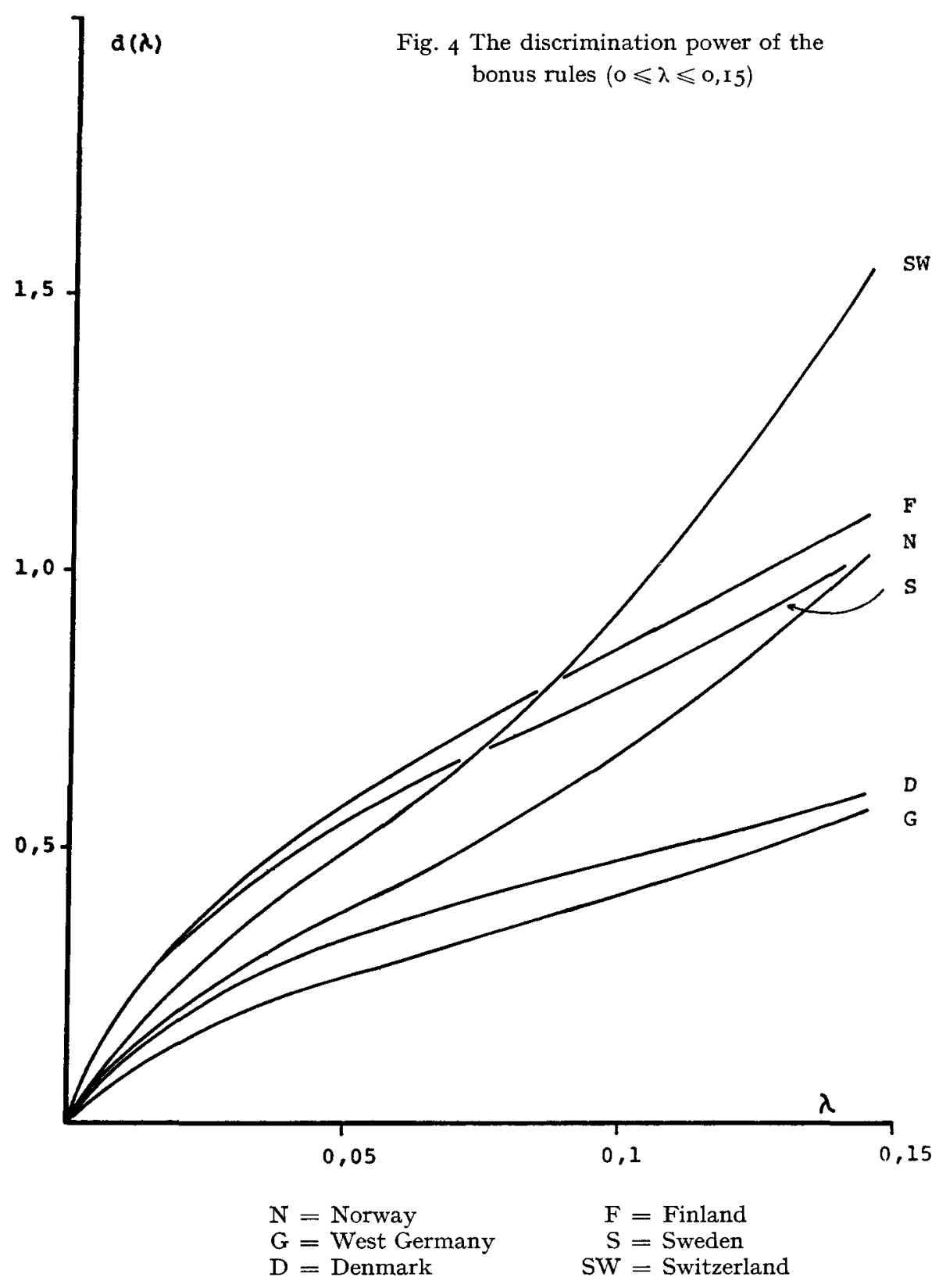


The bonus rules do not completely satisfy the above requirement: after two claims during one year or one claim during both of two years the new class will be o. In order to avoid this difficulty we add to the labels another digit, which is o or I depending on whether there was a claim year before or not. The transformations $T_{k}$ defining the bonus rules, and the premium vector $B$ will then be as follows: (the new policies are placed in class II)

\begin{tabular}{|c|c|c|c|c|}
\hline class & $T_{0}$ & $T_{1}$ & $T_{k}(k \geqslant 2)$ & $B$ \\
\hline oo & I I & oo & oo & I 33.33 \\
\hline I0 & $2 \mathrm{I}$ & oo & oo & IOO \\
\hline I I & $2 \mathrm{I}$ & ro & oo & IOO \\
\hline $2 I$ & $3 \mathrm{I}$ & IO & oo & 75 \\
\hline $3 \mathbf{I}$ & 3 I & 10 & oo & 56.25 \\
\hline
\end{tabular}

From the efficiency curves on page 2 I 2 we can see that the efficiency $\eta(\lambda)$ of the system for common values of $\lambda$ is rather small but this is not so unusual. Only the efficiencies of Finnish and Swedish systems attain larger values when $\lambda<0.05$. The function $\eta(\lambda)$ attains its maximum $\eta=0.32$ when $\lambda=0.55$. The discrimination power $d(\lambda)$ of the bonus rules (pp. 213-214) also seems to be relatively small for all values of $\lambda$, obviously the small number of classes is a restrictive factor.

\section{Finland}

The Finnish bonus system satisfies all the requirements stated in ref. I. There are 13 bonus classes labeled from o to 12 ; new policies are placed in the class 2 . The bonus rules and the premium vector are given in the table below:

\begin{tabular}{cccccccc}
\hline class & $T_{0}$ & $T_{1}$ & $T_{2}$ & $T_{3}$ & $T_{4}$ & $T_{k}(k \geqslant 5)$ & $B$ \\
\hline 0 & 2 & 0 & 0 & 0 & 0 & 0 & I40 \\
I & 2 & 0 & 0 & 0 & 0 & 0 & 1 20 \\
2 & 3 & I & 0 & 0 & 0 & 0 & 100 \\
3 & 4 & 2 & I & 0 & 0 & 0 & 100 \\
4 & 5 & 2 & I & 0 & 0 & 0 & 80 \\
5 & 6 & 3 & 2 & I & 0 & 0 & 70 \\
6 & 7 & 4 & 2 & I & 0 & 0 & 60 \\
7 & 8 & 5 & 3 & 2 & I & 0 & 50 \\
8 & 9 & 5 & 3 & 2 & I & 0 & 50 \\
9 & 10 & 5 & 3 & 2 & I & 0 & 50 \\
I0 & I I & 5 & 3 & 2 & I & 0 & 50 \\
I I & I2 & 5 & 3 & 2 & I & 0 & 50 \\
I2 & I2 & 6 & 4 & 2 & I & 0 & 40 \\
\hline
\end{tabular}


When $\lambda<0 . I$, the efficiency $\eta$ for this system has a value higher than for most other systems under study. One of the reasons for this is that the ratio between the premiums of the first and last classes has the great value 3.5 (while for example in Danish system the ratio is 2.4). The maximum value of $\eta(\lambda)$ is attained when $\lambda=0.35$. The discrimination power $d$ of the Finnish bonus rules for small values of $\lambda$, has higher value than for other systems. One reason for this is that the occurrence of a single claim in higher bonus classes $(i \geq 6)$ causes the return to the class 5 or 6 .

\section{Norway}

Also the bonus system of Norway can be treated without any modifications by means of the theory under consideration. There are I7 bonus classes (labeled from o to I6) and the initial class is the class Io. The premium vector $B$ and the bonus rules are given in the table below:

\begin{tabular}{|c|c|c|c|c|c|c|c|c|c|c|}
\hline class & $T_{0}$ & $T_{1}$ & $T_{2}$ & $T_{3}$ & $T_{4}$ & $T_{5}$ & $T_{6}$ & $T_{7}$ & $T_{k}(k \geqslant 8)$ & $B$ \\
\hline 0 & 8 & o & 0 & 0 & 0 & 0 & 0 & 0 & o & 300 \\
\hline I & 8 & 0 & 0 & 0 & o & 0 & 0 & o & 0 & 280 \\
\hline 2 & 8 & o & o & 0 & o & 0 & 0 & 0 & $o$ & 260 \\
\hline 3 & 8 & $\mathbf{I}$ & 0 & 0 & 0 & 0 & 0 & 0 & 0 & 240 \\
\hline 4 & 8 & 2 & 0 & 0 & 0 & o & 0 & o & 0 & 220 \\
\hline 5 & 8 & 3 & I & o & o & o & o & o & o & 200 \\
\hline 6 & 8 & 4 & 2 & o & o & o & 0 & o & o & I 80 \\
\hline 7 & 8 & 5 & 3 & I & o & o & o & o & o & 160 \\
\hline 8 & 9 & 6 & 4 & 2 & $\circ$ & o & o & o & o & $14^{\circ}$ \\
\hline 9 & IO & 7 & 5 & 3 & I & o & 0 & o & o & 120 \\
\hline IO & I I & 8 & 6 & 4 & 2 & 0 & 0 & 0 & 0 & 100 \\
\hline I I & I2 & 9 & 7 & 5 & 3 & I & 0 & 0 & 0 & 90 \\
\hline I 2 & I3 & Io & 8 & 6 & 4 & 2 & 0 & 0 & 0 & 80 \\
\hline r3 & I4 4 & I I & 9 & 7 & 5 & 3 & $I$ & 0 & 0 & 70 \\
\hline I 4 & I 5 & $\mathrm{I} 2$ & ro & 8 & 6 & 4 & 2 & 0 & 0 & 60 \\
\hline I5 & I6 & I3 & I I & 9 & 7 & 5 & 3 & I & 0 & $5^{\circ}$ \\
\hline 16 & I6 & $\mathrm{I}_{4}$ & 12 & IO & 8 & 6 & 4 & 2 & 0 & 40 \\
\hline
\end{tabular}

From the graph corresponding to the Norwegian system (page 2I2) we can see that for the moderate and great values of $(\lambda>0.2)$ the efficiency $\eta(\lambda)$ attain very high values. Only in the over-efficient system of Switzerland the function $\eta(\lambda)$ gets still higher values. The maximum value $\eta=I .09$ is attained at the point $\lambda=0.37$. Some reasons for this are easily founded. The bonus scale is very steep, 
the ratio between the premiums in classes 0 and $I 6$ is 7.5. Another reason for high values of $\eta(\lambda)$ with great values of $\lambda$ is the quick return from malus classes: After one claimfree period a policy in classes $0-7$ moves straight to the class 8 . This is also reason for the high values of the discrimination power (see fig. 3). For small values of the claim frequency the system seems not to be very efficient and also $d(\lambda)$ attains values smaller than the corresponding values of Finnish, Swedish or Swiss systems.

\section{Sweden}

As in the Danish system the assumption (ii) in ref. I. fails to be true. The transition to a certain class may depend on even six years old claims. However we can modify the Swedish bonus system by the same way as the Danish one. Originally there are seven bonus classes labeled from o to 6 . In addition to this label we take a second digit and define this to be $n$ if there have been no claims during last $n$ years. So the number of possible classes will be $2 I$, and the different classes and the transition rules are following: (the initial class is the class 00 )

\begin{tabular}{|c|c|c|c|c|c|}
\hline class & $T_{0}$ & $T_{1}$ & $T_{2}$ & $T_{k}(k \geqslant 3)$ & $B$ \\
\hline OO & I I & oo & oo & oo & IOO \\
\hline IO & $2 \mathrm{I}$ & oo & oo & oo & 80 \\
\hline I I & 22 & 00 & oo & oo & 80 \\
\hline 20 & $3 I$ & oo & oo & oo & $7^{\circ}$ \\
\hline $2 \mathrm{I}$ & 32 & oo & oo & oo & $7^{\circ}$ \\
\hline 22 & 33 & 00 & oo & 00 & $7^{\circ}$ \\
\hline 30 & $4^{\mathrm{I}}$ & IO & oo & 00 & 60 \\
\hline $3 \mathrm{I}$ & 42 & IO & 00 & OO & 60 \\
\hline 32 & 43 & IO & oo & ০o & 60 \\
\hline 33 & 44 & ro & oo & Oo & 60 \\
\hline $4^{\circ}$ & $5 \mathrm{I}$ & 20 & oo & 00 & 50 \\
\hline $4 \mathrm{I}$ & $5^{2}$ & 20 & oo & Oo & $5^{\circ}$ \\
\hline 42 & 53 & 20 & oo & oo & $5^{\circ}$ \\
\hline 43 & 54 & 20 & OO & 00 & $5^{\circ}$ \\
\hline 44 & 55 & 20 & oo & Oo & $5^{\circ}$ \\
\hline $5^{\mathrm{I}}$ & $5^{2}$ & 30 & IO & oo & $4^{\circ}$ \\
\hline 52 & 53 & 30 & IO & O० & $4^{\circ}$ \\
\hline 53 & 54 & 30 & 10 & oo & $4^{\circ}$ \\
\hline 54 & 55 & 30 & IO & 00 & $4^{\circ}$ \\
\hline 55 & 66 & 30 & IO & oo & $4^{\circ}$ \\
\hline 66 & 66 & 40 & 20 & 00 & 25 \\
\hline
\end{tabular}


The graphs of $\eta(\lambda)$ and $d(\lambda)$ are very similar to the graphs of the Finnish system. However, for $\lambda>0.5$ the efficiency of the Swedish system is rather low because there are no malus classes, and the transition to the highest bonus class is relatively slow. For smaller values of the claim frequency $(\lambda<0, I)$ the efficiency has the highest value of all systems under study, mainly because the maximum bonus is great, $75 \%$ of the premium of the first class. The discrimination power is also relatively high for common values $\lambda$.

\section{Switzerland}

In this system there are 22 bonus classes. The new policies are placed in the class 13 . The bonus rules and the premium vector $B$ are:

\begin{tabular}{|c|c|c|c|c|c|c|c|c|c|}
\hline class & $T_{0}$ & $T_{1}$ & $T_{2}$ & $T_{3}$ & $T_{4}$ & $T_{\mathbf{s}}$ & $T_{8}$ & $T_{k}(k \geqslant 7)$ & $B$ \\
\hline 0 & I & 0 & 0 & 0 & 0 & 0 & 0 & 0 & 270 \\
\hline I & 2 & 0 & 0 & 0 & 0 & 0 & 0 & 0 & 270 \\
\hline 2 & 3 & 0 & 0 & 0 & 0 & $o$ & o & o & 230 \\
\hline 3 & 4 & 0 & 0 & 0 & 0 & 0 & 0 & 0 & 230 \\
\hline 4 & 5 & I & o & 0 & 0 & 0 & 0 & o & 200 \\
\hline 5 & 6 & 2 & 0 & 0 & 0 & 0 & 0 & o & 200 \\
\hline 6 & 7 & 3 & 0 & 0 & 0 & 0 & 0 & o & I $70^{\circ}$ \\
\hline 7 & 8 & 4 & I & o & 0 & 0 & 0 & o & I 70 \\
\hline 8 & 9 & 5 & 2 & o & 0 & 0 & 0 & 0 & $I_{4}{ }^{\circ}$ \\
\hline 9 & IO & 6 & 3 & 0 & 0 & 0 & 0 & o & $I_{4} 0$ \\
\hline Io & I I & 7 & 4 & I & 0 & 0 & 0 & 0 & 120 \\
\hline I I & I2 & 8 & 5 & 2 & 0 & 0 & 0 & o & I 20 \\
\hline I 2 & I3 & 9 & 6 & 3 & 0 & 0 & 0 & 0 & IOO \\
\hline I3 & I4 & IO & 7 & 4 & I & 0 & o & o & 100 \\
\hline I4 & I5 & I I & 8 & 5 & 2 & 0 & 0 & $\mathbf{o}$ & 80 \\
\hline I5 & I6 & I 2 & 9 & 6 & 3 & 0 & 0 & o & 80 \\
\hline I6 & I7 & I3 & Io & 7 & 4 & I & 0 & 0 & 70 \\
\hline I 7 & I 8 & I4 & I I & 8 & 5 & 2 & 0 & 0 & $7^{\circ}$ \\
\hline I8 & I9 & I 5 & 12 & 9 & 6 & 3 & 0 & o & 60 \\
\hline I9 & 20 & I6 & I 3 & Io & 7 & 4 & I & 0 & 60 \\
\hline 20 & $2 \mathrm{I}$ & I7 & I4 & I I & 8 & 5 & 2 & 0 & 50 \\
\hline $2 I$ & $2 I$ & 18 & ${ } 5$ & I 2 & 9 & 6 & 3 & o & $5^{\circ}$ \\
\hline
\end{tabular}

The efficiency $\eta(\lambda)$ attains the very high maximum $\eta=1.87$ at $\lambda=0.24$. Also the discrimination power has its maximum (3.5) about at the same point. One reason for high values of $\eta$ is the steepness of the bonus scale. In addition, according to the bonus rules a policy moves three classes down if one claim occurs and one 
class up after a claimfree year. If a claim occurs about every thirth or fourth year $(\lambda \approx 0.25-0.3)$, the efficiency must attain a high value. The low values of $\eta$ and $d$ for $\lambda>0.5$ are obviously due to the slow transition to the highest bonus class.

\section{West Germany}

A bonus system used in West Germany is presented here: In the system there are 8 bonus classes and the initial class is the class 3 . The components of $B$-vector are the premiums of the "tariff group $M^{\prime \prime}$. The bonus rules and the premium vector are:

\begin{tabular}{ccccccc}
\hline class & $T_{0}$ & $T_{1}$ & $T_{2}$ & $T_{3}$ & $T_{k}(k \geqslant 4)$ & $B$ \\
\hline 0 & 3 & 0 & 0 & 0 & 0 & 150 \\
I & 3 & 0 & 0 & 0 & 0 & 130 \\
2 & 3 & 1 & 0 & 0 & 0 & 110 \\
3 & 5 & 2 & I & 0 & 0 & 100 \\
4 & 5 & 2 & I & 0 & 0 & 95 \\
5 & 6 & 4 & 2 & 0 & 0 & 90 \\
6 & 7 & 5 & 4 & I & 0 & 70 \\
7 & 7 & 6 & 5 & 2 & 0 & 50 \\
\hline
\end{tabular}

The efficiency and the discrimination power of this system are relatively great for $\lambda>0.5$. Similar features were found in the Norwegian system and a reason could be of the same kind: the quick return from malus classes $0-2$ to the class 3 . For small values of the claim frequency $\lambda$ the values of $\eta$ and $d$ are lower than the respective values of any other system under consideration. 